\title{
Post-pandemic agroecological urban landscaping priority for native, rustic and edible species
}

\section{Editorial}

Usually, urban landscaping uses ornamental plants with aesthetic characteristics adapted to the locations worked and the needs of users. When using native plants in landscape projects, two classifications are identified here, by their ornamental potential (ornamental plasticity) and by their functional, horticultural and landscape use. The first is when it is classified according to its ornamental potential, that is, in a proposition of "ornamental functional systematics", one can separate them into two large groups, the woody ones (tall size, which divides and creates the spaces) and herbaceous (covering the ground, but also where epiphytes are included). The second general categorization is to take into account the potential for landscape use (installed outdoors or as an indoor plant) or as a product of floriculture (flower or cut foliage).

However, during and after the pandemic of COVID 19, it is observed that it is no longer possible to imagine sustainable landscaping without edible plants. However, it is essential and mandatory today, to add the nutritional criterion of horticulture. This implies food for all types of fauna and not just humans, in a wide approach to the food chain and ecosystem services. Thus, in order to create sustainable landscape projects in the middle of the 21 st century, it is necessary to rely on the existing bibliographic production on local botanical resources. And from the observation of species in loco, generate ethnobotanical databases that should be the basis of future protocols for the production of native and rustic plants (a posteriori stage), necessarily using the productive system of organic and sustainable cultivation. The food must be of good quality and available to every consumers. Everyone, without exception or exclusion.

After the classifying these observed vegetables, field collections should be carried out to search for propagules, and then the implementation of local germplasm banks becomes of fundamental importance. They can be located in schools, universities or community associations (urban and rural) and even in public and private gardens, but preferably they must be have public access. These in situ germplasm banks, true botanical hortus, must consider the respective original regional habitats of the collected plants. To this end, they must have technical or volunteer managers who keep the database updated. These botanical rescue efforts for horticulture are observed with international organizations (FAO's HORTIVAR program, for example), with farmers guarding landraces seeds and in propositions of even famous contemporary landscape artists such as Piet Ouldolf and Gilles Clement. But after this long period of pandemic, it became evident that it is necessary to involve more volunteers who have the minimum technical knowledge in botany and horticulture necessary for a society that eagerly seeks knowledge for food autonomy. Thus, projects such as "Sauvages de ma rue" (Wild on my street) from the Natural History Museum of France are consolidated as a beautiful initiative in this regard.

Necessarily all these local urban agriculture initiatives within the landscape, involve recognizing and making available results of these local trials.

\author{
Volume 4 Issue 4 - 2020
}

\author{
Cláudia Petry \\ Agronomist, Researcher Teacher, Ph.D, Post Graduate Program \\ in Agronomy, University of Passo Fundo, Brazil
}

Correspondence: Cláudia Petry, Post Graduate Program in Agronomy, PPGAGRO, University of Passo Fundo, UPF, BR 285, São José, Passo Fundo, RS CEP 99052-900, Brazil, Email petry@upf.br

Received: July 0I, 2020 | Published: July 09, 2020

Each local initiative, when well portrayed, is a popular basic research, which reflects the respect for plant systematics and improvement (mass selection) applied, with ornamental, horticultural and landscape purposes. Therefore, what was observed during the pandemic period was that with less pressure from urban landscaping professionals on existing green spaces, native plant species were also able to express themselves and become visible in urban centers. Whether as wild plants, unconventional food plants or rustic plants.

And there was no charge for the priority of some aesthetic principles at the expense of ethical principles. Then, the same phenomenon that occurs with animal species is observed: a reappropriation of urban space by wild species, a spontaneous repopulation of these rustic, native species, originating from natural seeding. Hence the proof of the success of gardening proposals from landscapers such as Ouldolf and Clement as successful sustainability strategies. Whether they are cosmopolitan or spontaneous plants, but their existence in situ or on farm means that their ecophysiological needs have been met, without the establishment of experiments with statistical rigor or highly technified vegetable gardens.

So, the professionals, managers and technicians of this postpandemic landscaping, it is urgent to evaluate, in addition to the variables that include the ornamental plasticity, qualities and ornamental use, such as:type of foliage, flowers, trunk, shape and general aspect of the plant (ecological, attraction of birdlife, textures, perfume, toxicity and other particularities); it is also necessary to determine the possibility of individual or collective use and, above all, its use as a food plant. In order to meet the prerequisites for their permanence and resilience in the project sites, it is important to involve people's sensitivity, relating the cultural meanings and cultural symbolisms of these species, whether the recits in the literature or among the people involved in the projects. Because only what is well known is protected, as Albert Schweitzer and Francis Hallé remind us.

These places in the urban environment can be places for safeguarding plants at risk of extinction, sensitive native plants, spontaneous non-aggressive rustic or exotic species, but which have a reasonable development in degraded places. They are sites of vegetal 
memory. This is much more than being an artificial place and designed by some aesthetic principles of landscapers. It is essential to return to the meaning of life, to allow places where all vegetables can express themselves, due to the reestablishment of a balance between them, the environment, microorganisms and the animal kingdom. Human beings are part of it, but they should not be the only representatives and managers of these places. Today, the permaculture is one of the teachings of this ecological engineering that best applies this respect to life and biodiversity.

To illustrate this trend, par example, fruit species native to southern Brazil, such as the fruit tree Acca sellowiana (guava), which in its place of origin is not yet properly valued (but is already in other countries, such as New Zealand for example) among many others, can finally have a in situ memorial of thanks. Many exotic and spontaneous rustic species are an invaluable source of food (Portulaca sp., Talinum sp., Taraxacum $s p$. etc.). And they are not better valued due to pure botanical ignorance. If we consider the species of the annual cycle, which need a higher level of investment, it is necessary to invest in tests that evaluate those species with less energy and economic input and those of viable local production (by natural seeding). Even condiment and aromatic species of classical use (Petroselinum, etc.) naturally seeding if their production system is adapted to this objective. Just work as a system that allows the time flowering and seed production, providing this natural reseeding. The valued use of species adapted to different places such as neighborhood squares, workers' gardens, green roof and green walls, degraded or risky areas, it is observed that nutrient cycling becomes less expensive and that ecological succession occurs more easily, requiring less human intervention in the maintenance of these green spaces. The choice of these species in the minimally managed green spaces allows their existence to regionally express the history of human relations with vegetation. Like the minimalist garden in front of a museum in Siberia, whose vegetals species are those found in the stomach of mummies of extinct mammoths.

Emphasizing that in this historic post-pandemic moment, with all the consequences of the effects of confinement on our relations with nature and society, today more than ever, we all need to have food plants close at hand or our fingertips. Like the mammoths (If they were alive). Intelligent are the managers who make this a flag of democratic struggle for the life of all living beings. And above all, even more intelligents are so those who fight for the life of plants, autotrophic beings, who allow all other forms of life, the consumers. Unfortunately, through sad paths, pandemics will continue to teach us to value the essential.

\section{Acknowledgments}

None.

\section{Conflicts of interest}

Authors declare no conflict of interest exists. 